\title{
AUFSÄTZE
}

\section{Agnoli, die APO und der konstitutive Illiberalismus seiner Parlamentarismuskritik*}

\author{
Wolfgang Kraushaar
}

\section{Die Ambivalenz der Außerparlamentarischen Opposition}

Außerparlamentarische Bewegungen können kaum entstehen, wenn die Integrationsfähigkeiten eines parlamentarischen Systems und insbesondere der darin vertretenen Parteien nicht defizitär werden könnten. Die Konstitution derartiger Bewegungen ist immer auch ein Indiz für das Unvermögen des politischen Systems, soziale Widersprüche und die daraus resultierenden Interessenkonflikte aufzunehmen und als Widerstreit von Fraktionen innerhalb des Parlaments auszutragen.

Die in der zweiten Hälfte der 1960er Jahre entstandene Außerparlamentarische Opposition $(\mathrm{APO})^{1}$ war durch eine grundlegende Ambiguität bestimmt. Nicht wenige ihrer Akteure changierten zwischen Außer- und Antiparlamentarismus hin und her. Dabei traten immer stärker Gruppen in den Vordergrund, die der Bundesrepublik Deutschland, dem Rechtsstaat und seinen Institutionen nicht nur kritisch, sondern ablehnend gegenüberstanden. Antistaatlichkeit gehörte zu ihren Grundüberzeugungen. Misstrauen wurde zudem aus dem Verdacht geschöpft, dass der bundesdeutsche Staat bis in seine Spitze hinein - die politischen Vergangenheiten von Bundespräsident Heinrich Lübke und Bundeskanzler Kurt Georg Kiesinger wurden als exemplarisch betrachtet - von ehemaligen Funktionsträgern des NS-Regimes besetzt sei. Dieser Argwohn wurde auf die verschiedensten Institutionen übertragen und zu einem regelrechten Antiinstitutionalismus erweitert. $^{2}$

* Der Beitrag basiert auf einem Vortrag, den der Verfasser am 25. November 2006 auf einer Konferenz in der Villa Vigoni am Comer See gehalten hat, die den Titel „Krisenzeiten? 1968/ 1973 im deutsch-italienischen Vergleich" trug und eine Kontroverse ausgelöst hat. Vgl. Rainer Blasius, Seitenwechsel und Veränderung. 1968 bis 1973 im deutsch-italienischen Vergleich: Johannes Agnolis Parlamentarismuskritik, in: Frankfurter Allgemeine Zeitung vom 12. Dezember 2006.

1 Zur politikwissenschaftlichen Kontroverse über die Legitimität einer außerparlamentarischen Opposition vgl. Hans-Gerd Schumann (Hrsg.), Die Rolle der Opposition in der Bundesrepublik Deutschland, Darmstadt 1976, mit den Beiträgen von Andreas Hamann, Arnhelm Neusüß, Winfried Steffani, Margherita von Brentano, Hans Maier und Wolfgang Zeidler, S. 287 - 390.

2 Zur geschichtsphilosophischen Begründung der antiinstitutionellen Haltung vgl. Hans Martin Kuhn, Der lange Marsch in den Faschismus. Zur Theorie der Institutionen in der bürgerlichen Gesellschaft, West-Berlin 1974. 
Das Gespenst eines „neuen Faschismus“ war dort überall präsent. Die Nichtanerkennung des staatlichen Gewaltmonopols war eine logische Folge dieser Einstellung.

Im Winter 1968/69 hatte wegen der zunehmenden politischen Misserfolge außerparlamentarischer Aktionen ein Prozess der Umorientierung eingesetzt, der zu ersten Auflösungserscheinungen der APO und im Gegenzug zu einem Gründungsboom verschiedener Kleinorganisationen führte. Zunächst sollten so genannte Basisgruppen zum Medium einer politischen Transformation werden. Sie wurden an den Universitäten gegründet, griffen jedoch schon bald auf Stadtteile und Betriebe über. Der Schwerpunkt der politischen Aktivitäten sollte damit in jene gesellschaftlichen Bereiche verlagert werden, von denen man glaubte, dass dort der Klassenantagonismus noch lebendig sei.

Als nach der Bundestagswahl vom September 1969 SPD und FDP eine Regierung bildeten, die so genannte sozialliberale Koalition, zeigte sich, dass die außerparlamentarische Bewegung in einem unmittelbaren politischen Sinne fast vollständig gescheitert war. Zwar hatte sie mit dazu beigetragen, den Einzug der rechtsextremen NPD in den Bundestag zu verhindern ${ }^{3}$, ihre Hauptziele jedoch waren allesamt verfehlt worden. Innenpolitisch war bereits die Niederlage in der Anti-Notstandsbewegung entscheidend gewesen. Die vielbeschworene Einheit von Arbeiter- und Studentenbewegung, wie sie zum allgemeinen Erstaunen in Frankreich vorübergehend möglich geworden war, blieb in der Bundesrepublik eine Chimäre. Mit der Verabschiedung der Notstandsgesetze am 30. Mai 1968 hatte die APO ihren Zenit bereits überschritten. Die Struktur des Axel-SpringerVerlags blieb unangetastet, die Hochschulreform erwies sich rasch als Enttäuschung, der Vietnamkrieg dauerte unvermindert an, und die hochfliegenden revolutionären Erwartungen blieben auf der ganzen Linie unerfüllt.

Innerhalb von nur wenigen Monaten fiel mit dem Sozialistischen Deutschen Studentenbund (SDS) der eigentliche Motor der APO-Aktivitäten faktisch auseinander. Die dynamischen, sich als „antiautoritär“ begreifenden Strömungen schienen durch die nachlassende Mobilisierung auf der Straße und die infolge der sozialliberalen Koalition veränderte politische Lage wie paralysiert. Mit der neuen Bundesregierung unter dem sozialdemokratischen Kanzler Willy Brandt, der eine Reformpolitik einzuleiten versprach, entfielen die meisten Voraussetzungen zur Fortführung einer außerparlamentarischen Bewegung. Einige der von der APO freigesetzten Impulse, insbesondere im Bereich der Bildungspolitik, wurden aufgegriffen, andere hingegen eingedämmt oder ganz abgeschnitten. Die Bundesregierung legte einerseits mit dem Amnestiegesetz für Demonstrationsstraftäter ein Integrationsangebot vor, andererseits lieferte sie mit dem Radikalenerlass, durch den Systemgegner vom Staatsdienst ferngehalten werden sollten, bald darauf auch ein Zeichen der Abschreckung. Zwar wuchs das Potential links von der SPD quantitativ stark an, es stellte jedoch wegen seiner Diffusität keine einheitliche Kraft mehr dar und büßte dadurch viel vom Charakter einer politischen Herausforderung ein.

Den Ton in der Bewegung gaben nun radikal-orthodoxe Kräfte an - Neoleninisten und Maoisten. Während der größte Teil der alten APO von der SPD und der neu ge-

3 Nachdem es der NPD am 28. April 1968 mit 9,8 Prozent bei der baden-württembergischen Landtagswahl im Zeitraum von zwei Jahren zum siebten Mal gelang, in einen Landtag einzuziehen, schien sie auch durchaus realistische Aussichten zu besitzen, den Sprung in den Bundestag zu schaffen. Sie scheiterte am 28. September 1969 mit 4,3 Prozent jedoch relativ knapp an der Fünf-Prozent-Hürde. 
gründeten Deutschen Kommunistischen Partei (DKP) aufgesogen wurde, bildeten sich in kurzer Zeit vielerorts kommunistische Kadergruppen, die sich in völliger Verkennung ihrer wirklichen Rolle als Vorhut der Arbeiterbewegung begriffen. Die studentischen Speerspitzen der APO ernannten sich selbst zur proletarischen Avantgarde und glaubten sich so zur Führungselite einer nicht zu einer radikalen Systemveränderung neigenden Arbeiterschaft machen zu können. Als sich im März 1970 der SDS auch formell auflöste, waren die Weichenstellungen für die Entwicklung der radikalen Linken der siebziger Jahre bereits weitgehend vollzogen. Aus der APO waren vier Grundströmungen entstanden - eine, die dem Parlament konstruktiv, eine die ihm aus taktischen Gründen zustimmend und zwei, die ihm ablehnend beziehungsweise äußerst kritisch gegenüberstanden: eine reformistische, die ihre stärkste Bastion in der Jugendorganisation der SPD, den Jungsozialisten, besaß; eine traditionell kommunistische, die nach der Legalisierung einer kommunistischen Partei in der DKP ihre Heimat und in der Anbindung an die DDR und den Sowjetblock Halt fand; eine marxistisch-leninistische, die ihr Heil im „Proletkult" der 1920er Jahre und in der Gründung zumeist maoistischer Kaderorganisationen suchte und schließlich eine undogmatisch-neomarxistische, die im Sozialistischen Büro (SB) eine Art Netzwerkzentrale fand, deren Bedeutung allerdings erst im Laufe der Jahre sichtbar wurde.

Einerseits waren diese Strömungen durch eine hektische Aufbruchstimmung geprägt, andererseits aber saß die deprimierende Erfahrung einer grundlegenden politischen Niederlage immer noch tief. Diese Zwiespältigkeit führte bereits im Ansatz zu einer Verbissenheit in den meisten ihrer politischen Aktivitäten. Mit organisatorischer Entschlossenheit sollte nun das erreicht werden, was in der Form einer lockeren, zum Teil spontanen Protestbewegung nicht hatte vollbracht werden können. Deshalb musste zunächst die „Organisationsfrage“ gelöst werden.

Die Universitäten, an denen sich nach den zwischenzeitlich dominierenden Basisgruppen nun so genannte Rote Zellen auszubreiten begannen, wurden nicht länger mehr als der zentrale Ort angesehen, von dem aus die politische Arbeit zu organisieren sei. Die Auseinandersetzungen konzentrierten sich zunehmend auf außeruniversitäre Bereiche, auf Stadtteile und insbesondere auf Betriebe. Betriebsarbeit hatte für die entschiedensten der linksradikalen Gruppierungen Priorität, denn der Adressat war in erster Linie die Arbeiterschaft als das in ihren Augen einzig erfolgversprechende revolutionäre Subjekt. Es schien alles nur noch eine Frage der Bewusstseinsbildung zu sein, genauer, wie sich das „ökonomistische“ Arbeiterbewusstsein auf dem schnellsten Wege in ein „revolutionäres Klassenbewusstsein“ würde transformieren lassen können. Die Tatsache, dass es im September 1969 unter Stahlarbeitern zu wilden Streiks gekommen war, wurde als Zeichen für ein neues Selbstbewusstsein der Arbeiterklasse gewertet.

Die Fixierung auf die Arbeiterbewegung als dem vermeintlichen revolutionären Subjekt führte zur Entstehung zahlreicher K-Gruppen und pseudoproletarischer Parteien. Auch die im Mai 1970 erfolgte Gründung der terroristischen Rote Armee Fraktion (RAF), deren Mitglieder sich als „Leninisten mit Knarre“ verstanden, muss in diesem Zusammenhang gesehen werden. Die bewaffnete Kaderorganisation, die in den Jahren darauf wie keine andere das innenpolitische Klima in der Bundesrepublik vergiftete, gab vor, Teil eines größeren Ganzen, einer Art proletarischen Kampfzusammenhanges, zu sein. 
Die meisten der genannten Gruppierungen und Bewegungen waren außerparlamentarisch entstanden und hatten zum Parlamentarismus - wenn überhaupt - ein taktisches Verhältnis. Sie basierten immer noch auf einer, wenn auch höchst unterschiedlich akzentuierten Ablehnung von Parlament und Parteienstaat, deren theoretische Begründung bereits zu Beginn der Großen Koalition geliefert worden war. Diese Abwehrhaltung war so stark verankert, dass sie in den Augen der aus der APO hervorgegangenen Akteure keiner weiteren Überprüfung bedurfte. In gewisser Weise gehörte sie zu den als selbstverständlich angesehenen Grundüberzeugungen.

\section{2. "Die Transformation der Demokratie“}

Die Parlamentarismuskritik hatte in der außerparlamentarischen Linken bis 1969/70 eine wichtige Rolle gespielt. Sie war eng verknüpft mit einer Debatte über Möglichkeiten zur Bildung von Räten und zum Aufbau einer regelrechten Räterepublik, die zeitweilig als Antwort auf die als delegitimiert geltende parlamentarische Demokratie propagiert wurde. ${ }^{4}$ Die innerhalb der APO formulierte Kritik vollzog sich jedoch keineswegs im luftleeren Raum. Bereits Mitte der 1960er Jahre hatte sich in der Bundesrepublik eine Stimmung ausgebreitet, die seinerzeit von Ernst Fraenkel als „Parlamentsverdrossenheit“ bezeichnet worden war. ${ }^{5}$ Ein Unbehagen an der Politik im Allgemeinen wurde nicht nur als Kritik an der Bundesregierung, sondern mehr und mehr auch am Bundestag geäußert. Die Funktionsfähigkeit der Volksvertretung war auch von namhaften Politikwissenschaftlern in Zweifel gezogen worden. Die Rede war von einem regelrechten „Prozeß der Entmachtung und Entleerung des Bundestags" (Wilhelm Hennis) ${ }^{6}$, von einer zunehmenden Entkoppelung von Legislative und Exekutive. Die politischen Entscheidungen fielen wie es in meist unausgesprochener Anknüpfung an Carl Schmitts Diagnose vom Beginn der Weimarer Republik ${ }^{7}$ hieß - außerhalb der Volksvertretung, im Kabinett, den Einzelministerien, speziellen Ausschüssen oder anderen staatlichen Organen. Das Parlament reduziere sich auf ein bloßes Akklamationsinstrument der Regierung, es verwandle sich zum rhetorischen Beiwerk einer kaum zu kontrollierenden Machtpolitik.

Auf welchem Wege Ideen sich bei Akteuren durchsetzen und entsprechende Effekte erzielen, ist zumeist nur schwer zu bestimmen. Unbestreitbar ist jedoch, dass es theoretische Schriften gibt, die in der Akteurselite einer Protestbewegung für die vermeintliche Rationalisierung bestimmter politischer Haltungen und Einstellungen sorgen können. Und genau zu diesen zählte in herausragender, beinahe einzigartiger Weise eine Schrift des Politikwissenschaftlers Johannes Agnoli, der seit 1964 am Otto-Suhr-Institut der Frei-

4 Vgl. Wilfried Gottschalch, Parlamentarismus und Rätedemokratie. Mit einem Lesebuch, WestBerlin 1968. Dieser Teil der Auseinandersetzung, der sich aus der seinerzeit populären Vorstellung speiste, dass die gesellschaftliche „Basis“ die Macht übernehmen müsse, wird an dieser Stelle jedoch nicht weiter verfolgt.

5 Ernst Fraenkel, Ursprung und politische Bedeutung der Parlamentsverdrossenheit, in: Der Politologe, 8. Jg. (1967), H. 2, S. $17-25$.

6 Wilhelm Hennis, Haben wir ein faules Parlament? Wünsche an den neuen Bundestag - Die Reform ist unausweichlich, in: Die Zeit vom 22. Oktober 1965, S. 7.

7 Carl Schmitt, Die geistesgeschichtliche Lage des heutigen Parlamentarismus, München / Leipzig 1923. 
en Universität Berlin lehrte, das eines der theoretischen Zentren der Studentenbewegung, der APO und letztlich der 68er-Bewegung insgesamt war.

Mit seinem 1967 erschienenen Traktat „Die Transformation der Demokratie“ hatte er eine offenbar zeitgerechte Radikalkritik der Bonner Demokratie vorgelegt ${ }^{8}$, die weit über die APO hinaus als die Begründung außerparlamentarischer Opposition schlechthin rezipiert und in gewisser Weise kanonisiert wurde. ${ }^{9}$ Sein Buch, das der liberal-konservative Publizist Sebastian Haffner in einer der ersten Rezensionen als „ein kleines Meisterwerk“ bezeichnete ${ }^{10}$ und der Politikwissenschaftler Dieter Senghaas wegen seiner Differenziertheit rühmte ${ }^{11}$, passte in die Zeit der ersten Großen Koalition wie ein theoretischer Lückenfüller. Später wurde es gar als „Bibel der außerparlamentarischen Opposition" insgesamt (Rudolf Walther) bezeichnet. ${ }^{12}$

Den Anstoß, sich näher mit dem politischen System der Bundesrepublik zu befassen, hatte der Politikwissenschaftler Ossip K. Flechtheim gegeben. Agnoli war deshalb im Februar 1965 zusammen mit Winfried Steffani nach Bonn gereist, um in der Bundeshauptstadt Informationen zu sammeln. Nach der Veröffentlichung erster Ergebnisse unter der Überschrift „Il regime parlamentare nella repubblica federale“ in der von Lelio Basso herausgegebenen Zeitschrift Problemi del socialismo, die nach seiner eigenen Darstellung als Rohentwurf seines Werkes angesehen werden kann, lernte er bei einem Vortrag über das Verhältnis von „Verfassung und Herrschaft“ in Köln den Psychologen Peter Brückner kennen. Dessen Versuch, Agnolis Text in einem von ihm herauszugebenden Sammelband über die Bundesrepublik zu publizieren, scheiterte am Einspruch des Fischer Verlags. Das wiederum veranlasste Brückner dazu, seinen Auftrag zurückzugeben. Er machte nun den Vorschlag, zu zweit ein Buch über den Verfassungsstaat und das politische Bewusstsein zu

8 Johannes Agnoli / Peter Brückner, Die Transformation der Demokratie, West-Berlin 1967; hier zitiert nach der identischen Ausgabe Frankfurt am Main 1968. Da Brückner nicht Co-Autor war und mit seinem unter dem Titel „Die Transformation des demokratischen Bewußtseins" (S. 89 - 191) publizierten Teil in der Rezeption so gut wie keine Rolle gespielt hat, bleibt seine psychologisch verfahrende Argumentation in diesem Zusammenhang unberücksichtigt.

9 Vgl. in diesem Zusammenhang die Aufnahme einer Zusammenfassung seines Buches in einem repräsentativen Reader: Johannes Agnoli, Thesen zur Transformation der Demokratie und zur außerparlamentarischen Opposition, in: Ulrich Matz (Hrsg.), Grundprobleme der Demokratie, Darmstadt 1973, S. $461-471$.

10 „Mit dem parlamentarischen Mechanismus ist für die Demokratie in Deutschland nichts mehr anzufangen, er ist bereits zu gründlich umfunktioniert worden. Wer heute noch etwas für die Demokratie auszurichten versucht, indem er in eine der etablierten Parteien geht, läuft in eine Falle; und für die Aussichtslosigkeit neuer Parteigründungen ist gesorgt. Die Wiederherstellung eines demokratischen Lebens muß heute bereits einen Weg am Parlament vorbei suchen und außerparlamentarische Organe finden. Überspitzt gesagt: Die Sache der Demokratie ist heute bereits wieder, kaum weniger als 1848 und 1918, eine revolutionäre Sache." Sebastian Haffners Monatslektüre, in: konkret, Nr. 3, März 1968, S. 38.

11 „Selten wurde kritische, auf politische Emanzipation hinwirkende Theorie der Demokratie in den vergangenen Jahren in vergleichbarer Differenziertheit vorgetragen." Dieter Senghaas, Subtiler Jargon, in: Die Zeit vom 24. Mai 1968, S. 11.

12 „Wenn es ein Buch gegeben hat, das man als Bibel der außerparlamentarischen Opposition (APO) bezeichnen kann, dann war es ,der Agnoli', das heißt das Buch mit dem Titel ,Die Transformation der Demokratie', das 1967 erstmals erschienen ist." Rudolf Walther, Vom Bewunderer Mussolinis zum Wortführer der APO, in: Die Zeit vom 31. Dezember 2004, Hervorhebung nicht im Original. 
publizieren. Ursprünglich hätte der Titel des Projekts unverändert „Verfassung und Herrschaft" lauten sollen. Dann sei jedoch mit Nico Neumann der Lektor des Voltaire Verlags, in dem der Band zunächst erschien, auf die Idee gekommen, die Überschrift des ersten Abschnitts als Gesamttitel zu verwenden. So soll es nach Agnolis eigener Darstellung für sein bekanntestes Werk zum Namen „Die Transformation der Demokratie“ gekommen sein - zu einem Namen, der ihm später selbst als nicht ganz unproblematisch erschienen sein will. ${ }^{13}$ Mehr als zwanzig Jahre später räumte er jedenfalls im Rahmen einer Ringvorlesung an der Freien Universität ein, dass der Titel gar nicht von ihm stamme. Freimütig bekannte er, dass er „eigentlich nicht gerne von Demokratie im Zusammenhang mit dem bürgerlichen Verfassungsstaat" sprechen würde. ${ }^{14}$ Wo der Titel seinen Ursprung hatte, wollte er jedoch noch immer nicht verraten.

Als Ausgangspunkt der „Transformation der Demokratie“ skizziert Agnoli ein Grundproblem des parlamentarischen Systems: Vom Anspruch her soll das Volk Träger der Staatsgewalt sein, in Wirklichkeit jedoch ist es in seiner Gesamtheit nicht regierungsfähig. Die durch den Wahlakt ausgewiesene Repräsentation muss deshalb das Handeln Weniger für Alle legitimieren. Unter diesem Ausgangsverhältnis, so Agnoli, vollziehe sich nun im modernen parlamentarischen System ein tiefgreifender Strukturwandel: Die demokratischen Parteien, Verfassung und Staat entwickelten sich in autoritär orientierte vor- oder antiparlamentarische Formen zurück. ${ }^{15}$ Agnoli bezeichnet diesen Prozess als „Involution“. Mit diesem Terminus charakterisiert er die „Transformation der Demokratie", die auf nichts anderes als eine Camouflage autoritärer, ihrer Tendenz nach undemokratischer Herrschaftsformen aus sei, als eine Kette historischer Rückschritte. Besonderes Merkmal der allenthalben zu beobachtenden Involutionstendenzen sei, dass mit ihnen die Verfassungsnormen und -formen umfunktioniert worden seien. Dadurch stelle sich ein paradox erscheinender Zustand ein: Das Instrumentarium des Verfassungsstaates werde unter Beibehaltung seiner Normen verfeinert. Damit werde jedoch nicht das demokratische Verfahren gestärkt, sondern die Machtapparatur im Dienste der Kapitalinteressen weiter perfektioniert.

Das politische System nehme so in immer stärkerem Maße die Form eines korporatistischen Blocks an. Organisationen, die einstmals bestimmte Interessen vertreten hätten, die mit anderen nahezu zwangsläufig in Konflikt geraten mussten, verwandelten sich insgeheim in staatspolitische Vereinigungen. Nicht mehr die offene Austragung gegensätz-

13 „Die ursprüngliche Fassung traf das Richtigere, hätte vielleicht auch interessierte Fehldeutungen verhindert, aber dem schmalen Bändchen weit weniger Erfolg beschert." Johannes Agnoli, Zwanzig Jahre danach. Kommemorativabhandlung zur "Transformation der Demokratie“, in: Probleme des Klassenkampfs. Zeitschrift für politische Ökonomie und sozialistische Politik, 16. Jg. (1986), März, Nr. 62, S. 7 - 40, S. 12.

14, „[... [ dieser Titel ,Transformation der Demokratie“ stammt gar nicht von mir, denn ich rede eigentlich nicht gerne von Demokratie im Zusammenhang mit dem bürgerlichen Verfassungsstaat, sondern eben vom parlamentarischen, jedenfalls bürgerlichen Verfassungsstaat." Verfassungskritik der Außerparlamentarischen Opposition; Teilnehmer: Johannes Agnoli und Ulrich K. Preuß; Diskussionsleitung: Werner Süß; www.infopartisan.net/archive/1968/29707.html [17. November 2006].

15 „Die Parteien trennen sich von der eigenen, aktuellen oder potentiellen gesellschaftlichen Basis und werden zu staatspolitischen Vereinigungen." Johannes Agnoli, Transformation, a.a.O., S. 33 . 
licher Interessen sei angesagt, sondern das möglichst reibungslose Einfinden in staatliche Regelungsprozeduren. Der Antagonismus der Klassengesellschaft, der sich sozioökonomisch unvermindert perpetuiere, reduziere sich auf die scheinhafte Pluralität von Parteien, die in Wirklichkeit jedoch wie nach dem Muster einer Einheitspartei funktionierten. ${ }^{16}$ Aus Klassen- seien Volksparteien geworden, deren Konkurrenzgebaren immer mehr zum Schein werde. Und das Parlament, die eigentliche Krone der westlichen Demokratien, spiele „dem demos gegenüber“ die Rolle eines „Transmissionsriemens der Entscheidungen politischer Oligarchien "17. Damit löse sich die ursprünglich am Marktmodell orientierte parlamentarische Demokratie nicht einfach auf, sondern transformiere sich ohne Bruch ihres formal rechtsstaatlichen Selbstverständnisses in Organe eines autoritären Staates. Die Gefahr der Inthronisierung eines faschistischen Herrschaftsmodells, das sich demnach auch ohne die Terrorisierung des politischen Gegners durch Sturmtruppen etablieren könne, weil es sich mit den Mitteln des Verfassungsstaates klammheimlich durchzusetzen wisse, wird durch diese Darstellung nahegelegt.

Agnoli zieht aus seiner Argumentation in eigens für das theoretische Organ des SDS verfassten Thesen politische Schlussfolgerungen für die $\mathrm{APO}^{18}$ : Da es keine immanente Möglichkeit gebe, die Involutionstendenzen zu stoppen oder gar umzukehren, sei jede Form innerparlamentarischer Opposition kontraproduktiv. Sie könne keine andere Rolle als die eines Integrationsinstrumentes spielen. Einer außerparlamentarischen Opposition stünden grundsätzlich zwei Richtungen offen: Einerseits könnte sie sich zu einem Wahlverein entwickeln, dann führe ihr Weg nach „rechts“; andererseits könnte sie die Antagonismen weiter verschärfen, dann führe ihr Weg nach „links“. Eine außerparlamentarische Opposition müsse nicht per se antidemokratisch sein. Wenn das Parlament jedoch selbst antidemokratisch würde, könne der Kampf für mehr Demokratie nur noch antiparlamentarisch ausgefochten werden. Da die Bundesrepublik in ihrer Kerntendenz „faschistisch" sei ${ }^{19}$, bleibe einer außerparlamentarischen Opposition schließlich nichts anderes übrig, als einen antiparlamentarischen Kampf zu führen. Die APO wird hier also als Vorhut zum Klassenkampf betrachtet, der sich auch direkt gegen den Parlamentarismus richten müsse.

Hinter Agnolis Argumentation steckt, ohne dass der Ahnherr der „klassischen“ Demokratie- und Staatstheorie mit einem Wort erwähnt würde, unverkennbar ein rousseauistischer Kern. Agnoli geht implizit von der von Jean-Jacques Rousseau ${ }^{20}$ propagierten

16 Der von Agnoli vorgegebenen Richtung folgten in den 1970er Jahren zahlreiche Politikwissenschaftler und sprachen von der zunehmenden Gefahr, dass in der Bundesrepublik aus dem politischen System ein „Einparteienstaat" werden könne. Vgl. Wolf-Dieter Narr (Hrsg.), Auf dem Weg zum Einparteienstaat, mit Beiträgen von Johannes Agnoli, Hermann Kaste / Joachim Raschke, Alf Mintzel, Hermann Scheer, Theo Schiller, Hans See und Jürgen Seifert, Opladen 1977.

17 Johannes Agnoli, Transformation, a.a.O., S. 68.

18 Johannes Agnoli, Thesen zur Transformation der Demokratie und zur außerparlamentarischen Opposition, in: Neue Kritik, 9. Jg. (1968), Nr. 47, S. $24-33$.

19 „Die Bundesrepublik Deutschland ist kein faschistischer Staat, aber die Kerntendenz der Abwehr gegen Emanzipation in der Bundesrepublik, im bürgerlichen Staat, ist faschistisch. D. h. konkreter formuliert und auch historischer: Der Umschlag in den offenen Faschismus ist dem bürgerlichen Staat immanent." Johannes Agnoli, Autoritärer Staat und Faschismus, in: Detlev Claussen / Regine Dermitzel (Hrsg.), Universität und Widerstand. Versuch einer politischen Universität in Frankfurt, Frankfurt am Main 1968, S. 57.

20 Bereits in der an seine Genfer Mitbürger gerichteten Widmung seines 1755 verfassten „Dis- 
Identität von Regierten und Regierenden aus ${ }^{21}$ und muss deshalb das auf dem Repräsentationsgedanken basierende parlamentarische System aus grundsätzlichen Erwägungen verwerfen. Daraus resultiert auf der einen Seite eine prinzipielle Gegnerschaft zum Pluralismus $^{22}$ und den Parteien als ihren konkreten politischen Manifestationen ${ }^{23}$ sowie auf der anderen die Gefahr, totalitarismusverdächtigen Alternativmodellen wie dem Rätesystem, das bekanntlich keine Gewaltenteilung kennt, das Wort zu reden. ${ }^{24}$ Unter Agnolis Vorannahmen hängt die Beurteilung der bundesdeutschen Demokratie also gar nicht auch wenn er durchweg den Eindruck zu erwecken versucht, als habe er das im Sinn von irgendwelchen empirischen Einzelergebnissen ab; sie ist keine gradualistisch zu beantwortende Frage nach einem „besseren“ oder „schlechteren“ Funktionieren. Die Verurteilung des Parlamentarismus ist normativ vorab gesetzt.

Agnolis Analyse „passte“ so gut in ihre Zeit, weil sie unter den Rahmenbedingungen der Großen Koalition und auf dem Höhepunkt des Konflikts um die Einführung der Notstandsgesetze zugleich auch eine suggestive Qualität besaß. Sie legte nahe, dass gegen die angeblich drohende Gefahr eines „,neuen Faschismus“ nur der Klassenkampf eine wirksame Gegenwehr darstellte. Wenngleich er in seinem Text „nur“ von „Fundamentalopposition“ spricht ${ }^{25}$, so hält er in den bereits erwähnten Thesen nicht nur den Klassenkampf für den ersten Schritt zur Verwirklichung von Demokratie, sondern unter bestimmten Voraussetzungen auch den Umschlag von einer außerparlamentarischen Opposition „in einen offenen, antiparlamentarischen Kampf ${ }^{\prime 26}$ für denk- und wünschbar. In

cours sur L'Inégalit?“ hatte Rousseau das Modell seiner Demokratievorstellung skizziert: „Ich hätte mir gewünscht, in einem Land geboren zu sein, in dem der Souverän und das Volk einerlei Interesse haben, damit alle Bewegungen der Maschinerie [gemeint ist hier der Staatsapparat, W. K.] auf die allgemeine Gültigkeit abzielen. Dieses kann nirgends anders sein, als wo der Souverän und das Volk in einer einzigen Person vereinigt sind. Folglich würde ich nur wünschen, unter einer mit Weisheit gemäßigten demokratischen Regierung geboren zu sein." Jean-Jacques Rousseau, An die Republik zu Genf, [Widmung zu der] Abhandlung über den Ursprung und die Grundlagen der Ungleichheit unter den Menschen, in: ders., Sozialphilosophische und Politische Schriften, München 1981, S. 42.

21, „[...] das Identitätsverhältnis zwischen Regierten und Regierenden, das dem demokratischen Gedanken zugrunde liegt [...].“ Johannes Agnoli, Transformation, a.a.O., S. 70.

22 Für Agnoli ist Pluralismus eine Fiktion und der Gegenbegriff zum Antagonismus. So behauptet er, dass die „Transformation des Verfassungsstaates“ die „Reduktion des Antagonismus auf den Pluralismus" widerspiegele. Ebenda, S. 24. Während es bei der Austragung von Differenzen beim Pluralismus um Konsens, im Zweifelsfall um die Herstellung von Kompromissen geht und damit garantiert ist, dass dessen Rahmenbedingung, der Rechtsstaat, nicht angetastet wird, so geht es beim Antagonismus um das Gegenteil einer einvernehmlichen Lösung: um die Auflösung des Widerspruchs im offenen Konflikt, letztlich um die Austragung eines Kampfes.

23 „Die Parteien trennen sich von der eigenen, aktuellen gesellschaftlichen Basis und werden zu staatspolitischen Vereinigungen." Ebenda, S. 33.

$24 \mathrm{Zu}$ den möglichen totalitären Implikationen des Rousseauschen Demokratiemodells vgl. Jacob Leib Talmon, Die Ursprünge der totalitären Demokratie, Köln / Opladen 1961.

25 „Nur Fundamentalopposition ist daran interessiert, politische und gesellschaftliche Mißstände schonungslos aufzudecken." Johannes Agnoli, Transformation, a.a.O., S. 81.

26 „Es kann aber im Verlauf bestimmter politischer Prozesse zu einem Umschlag der außerparlamentarischen Opposition in einen offenen, antiparlamentarischen Kampf kommen [...], sofern Parlamente trotz demokratischer Wahlakte, aus denen sie hervorgehen, antidemokratisch funktionieren, muß der Kampf für die Demokratie in antiparlamentarischer Praxis geführt werden." Johannes Agnoli, Thesen, a.a.O., S. 31. 
seiner ganzen Argumentation geht es ihm darum, den angeblich fiktiven Charakter des Parlamentarismus aufzudecken und den sozialen Antagonismus wieder sichtbar zu machen.

\section{Die Politik des "trasformismo" und die Lehre von der "trasformazione della democrazia"}

Die Grundgedanken von Agnolis Parlamentarismuskritik sind alles andere als originell, denn sie stammen aus Italiens präfaschistischer Ära. Vor dem Ersten Weltkrieg lautete das zentrale Stichwort in der italienischen Politik „trasformismo“. Wie kein anderes charakterisierte es das staatliche Handeln des wichtigsten Politikers dieser Ära, die des liberalen Ministerpräsidenten Giovanni Giolitti. Seine Überzeugung bestand im Kern darin, dass eine wirkungsvolle Opposition nur durch die Aufnahme der oppositionellen Kräfte in die „classe di governanti“ verhindert werden könne. Diese Transformation der politischen Klasse, der es um den Preis ihres Untergangs gelingen müsse, die sozioökonomisch widerstrebenden Kräfte zu integrieren, sichere die Stabilität des liberalen Systems. Die herrschende Elite müsse deshalb bestrebt sein, ihre Parlamentsmehrheiten nach pragmatischen und nicht nach programmatischen Kriterien zustande zu bringen. Grundfigur dieser Politik war die Herstellung von Kompromissen vor allem in zweierlei Hinsicht: als Kompromiss zwischen der alten und der neuen, der reaktionären und der modernen Bourgeoisie und als Kompromiss zwischen dem Staat und den Organisationen der Arbeiterbewegung.

Die Politik des „trasformismo“ der Ära Giolitti ist von zwei Autoren theoretisiert und damit in gewisser Weise kanonisiert worden: von dem Rechts- und Politikwissenschaftler Gaetano Mosca sowie dem Nationalökonomen und Soziologen Vilfredo Pareto. ${ }^{27}$

Mosca ist vor allem durch seine Klassen- und Elitentheorie bekannt geworden. ${ }^{28}$ Macht und Herrschaft sind seine zentralen Kategorien. Die für ihn entscheidende Frage lautet, wie es einer Minderheit gelingen kann, die Macht nicht nur an sich zu reißen, sondern sie durch die Nutzung besonderer organisatorischer Kalküle auch zu behalten. Für die „classe politica“ ist entscheidend, wie sie sich durch ihre jeweilige „formula politica", die aus nichts anderem als einer pseudo-logischen Ideologie besteht, als überzeugungsfähig erweist. ${ }^{29}$ Eine Fortentwicklung dieser Macht- und Elitentheorie findet sich

27 Vgl. Peter Hübner, Herrschende Klasse und Elite. Eine Strukturanalyse der Gesellschaftstheorien Moscas und Paretos, West-Berlin 1967.

28 „In allen Gesellschaftsordnungen, von den primitivsten im Aufgang der Zivilisation bis zu den vorgeschrittensten und mächtigsten, gibt es zwei Klassen, eine, die herrscht, und eine, die beherrscht wird. Die erste ist immer die weniger zahlreiche, sie versieht alle politischen Funktionen, monopolisiert die Macht und genießt deren Vorteile, während die zweite, zahlreichere Klasse von der ersten befehligt und geleitet wird. Diese Leitung ist mehr oder weniger gesetzlich, mehr oder weniger willkürlich oder gewaltsam und dient dazu, den Herrschenden den Lebensunterhalt und die Mittel der Staatsführung zu liefern." Gaetano Mosca, Die herrschende Klasse. Grundlagen der politischen Wissenschaft, Bern 1950, S. 53.

29 „Jede politische Klasse [...] sucht ihre Macht durch ein abstraktes Prinzip zu rechtfertigen, durch eine Formel, die wir politische Formel nennen werden: Wenn man sagt, daß die Autorität aller Träger eines Staatsamtes vom Souverän stamme, der sie seinerseits wiederum von Gott 
bei Pareto. Auch er arbeitet mit einer dualistischen Vorstellung. Die Gesellschaft setzt sich aus zwei Teilen zusammen - der „nicht ausgewählten Klasse“ und der „ausgewählten Klasse“; letztere wiederum zerfällt in die „herrschende Elite“ und die „nichtherrschende Elite "30. Auch für ihn ist entscheidend, wer an die Macht gelangt und diese mit Hilfe von „Derivationen“ - so lauten bei ihm die ideologischen Begründungsmuster - aufrechtzuerhalten in der Lage ist. Die Politik wird bestimmt durch eine fortwährende Zirkulation verschiedener Eliten. Sie kann sich in evolutionärer ebenso wie in revolutionärer Form vollziehen. Ausschlaggebend ist ihr machtpolitischer Erfolg.

Kein anderer Theoretiker wird in Agnolis Schrift so häufig genannt wie Pareto. Deutlicher noch wird er in Thesen, die er 1968 zur Erläuterung seines Buches publiziert hat. Dort heißt es: „Pareto hatte 1922 Mussolini den Rat erteilt, um der Stabilisierung der Macht willen das Parlament in gewandelter Form weiter am Leben zu lassen: Massen, die demokratischen Gefühlen zuneigen, seien am besten durch ein Organ neutralisierbar, das ihnen die Illusion einer Beteiligung an der staatlichen Macht vermittelt. Nicht die gänzliche Abschaffung des Parlaments mache den Neuen Staat stark, sondern die Verlegung der Entscheidungsbefugnisse vom Parlament in den engeren Kreis nicht öffentlich tagender ,Eliten'. Darin lag nach Pareto auch der historische Sinn und der bürgerliche Klassenauftrag der faschistischen Transformation des Staates." ${ }^{11}$ In Paretos Vorstellung konnte schließlich immer nur eine Elite eine andere ablösen. Eine Behauptung wie die, dass das Volk herrsche, war für ihn nichts anderes als eine typische „Derivation“, also eine pseudo-logische Erklärung. ${ }^{32}$ Tatsächlich hatte Agnoli genau mit diesem Gedanken im Jahr zuvor sein Traktat begonnen.

Direkter noch wurde er in einer Rede, die er im Mai 1968 während der damals wegen der bevorstehenden Verabschiedung der Notstandsgesetze erfolgten Besetzung der Frankfurter Universität und ihrer Umbenennung von Johann-Wolfgang-Goethe- in KarlMarx-Universität hielt. Dort versuchte er der Ansicht entgegenzutreten, dass sich Faschismus und Parlamentarismus zwangsläufig ausschließen müssten: „Die Möglichkeit eines parlamentarischen Faschismus, und d.h., die Möglichkeit eines antidemokratisch gewordenen Parlamentarismus, ist darin begründet, ob es gelingt, das Parlament soweit zu entmachten, daß die eigentlichen Entscheidungsgremien in, wie Pareto sagt, ,nichtöffentlich tagende Eliten' verlegt und die Entscheidungen von Masseneinflüssen freigehalten werden. Gelingt dieser entscheidende Schritt, und für Pareto ist das der eigentliche Kern eines modernen bürgerlichen Staates, so muß allerdings für die demokratisch freigesetzten Impulse der Bevölkerung immer ein Auffangorgan vorhanden sein, und dieses Auffang-

herleite, dann gebraucht man eine politische Formel; der Glaube, alle Macht beruhe auf dem Willen des Volkes, ist eine weitere politische Formel." Gaetano Mosca, Sulla teorica dei governi e sul governo parlamentare, Turin 1925, S. 36.

30 Vgl. Vilfredo Paretos System der allgemeinen Soziologie, hrsg. von Gottfried Eisermann, Stuttgart 1962, \$2034, S. 150.

31 Johannes Agnoli, Thesen, a.a.O., S. 25, Hervorhebungen nicht im Original.

32 „Ein Regime, bei dem das ,Volk' seinen ,Willen' ausdrückt - vorausgesetzt, aber nicht eingeräumt, es habe einen -, ohne ,politische Maschine', Intrigen und Cliquen existiert allein als frommer Wunsch von Theoretikern." Vilfredo Paretos System, a.a.O., $\$$ 2259, S. 196. 
organ ist das Parlament."33 Aus dieser Sicht besteht die Aufgabe des Parlaments also in nichts anderem als darin, einen Raum für die Fiktion einer Volksherrschaft zu schaffen.

Selbst der Titel von Agnolis programmatischer Kritik war nichts anderes als die wörtliche Übersetzung eines Pareto-Aufsatzes. ${ }^{34}$ Pareto hatte 1920 in der Rivista di Milano einen Artikel unter der Überschrift „Trasformazione della democrazia“ veröffentlicht, die ein Jahr später auch zum Titel einer Aufsatzsammlung wurde. ${ }^{35}$ Darin behauptete er, dass die repräsentative Demokratie nichts anderes als eine "plutokratische Demagogie“ sei, die dem Untergang geweiht wäre. Ihm schwebte stattdessen die Entstehung einer außerparlamentarischen Elite vor, die die Macht im Staate erringen solle.

Manches von dem, was Pareto gedacht hat, ist offenbar von Mussolini in die politische Praxis umgesetzt worden. ${ }^{36}$ Von dessen Biographin Margherita G. Sarfatti ist der bereits im August 1923 verstorbene Pareto als jener seiner Lehrer bezeichnet worden, der „den tiefsten und nachhaltigsten Einfluß auf ihn ausgeübt" habe. ${ }^{37}$ Auch wenn die Frage, ob es jemals Beziehungen praktischer Natur zwischen Pareto und Mussolini gegeben hat, als ungeklärt gilt, so darf die geistige Beeinflussung des „Duce“ durch den prominenten Soziologen als unbestreitbar angenommen werden. ${ }^{38}$ Der Historiker Renzo de Felice, zu dem Agnoli bei einem Forschungsaufenthalt Mitte der 1960er Jahre in Rom engen Kontakt hatte, zitiert sogar eine an Mussolini am Vorabend des faschistischen Konvents von Neapel übermittelte Aufforderung Paretos: „Heute oder nie!“39 Danach erfolgte im Oktober 1922 der „Marsch auf Rom“ - ein Marsch, den Mussolini bekanntlich von Mailand aus im komfortablen Schlafwagen eines Zuges zurücklegte. ${ }^{40}$

33 Johannes Agnoli, Autoritärer Staat und Faschismus, a.a.O., S. 48, Hervorhebungen nicht im Original.

34 Darauf hat bereits 1974 im Rahmen einer Festschrift für Arnold Gehlen hingewiesen: Piet Tommissen, Vilfredo Pareto und der italienische Faschismus, in: Ernst Forsthoff / Reinhard Hörstel (Hrsg.), Standorte im Zeitstrom. Festschrift für Arnold Gehlen zum 70. Geburtstag am 29. Januar 1974, Frankfurt am Main 1974, S. 365 - 391, S. 366.

35 Vilfredo Pareto, Trasformazione della democrazia, Milano 1921.

36 Bereits 1929 gelangte Max von Binzer, der sich mit der Beziehung zwischen Pareto und Mussolini beschäftigt hat, zu dem Ergebnis: „Jedenfalls findet man in Mussolinis praktischer Politik vieles, was Pareto gedacht, gesagt und geschrieben hatte, so daß man unbedingt von einer Beeinflussung und Vertiefung sprechen kann, ja Robert Michels nennt den Einfluß sogar einen ,gewaltigen'." Ders., Die Führerauslese im Faschismus, Langensalza 1929, S. 7, Hervorhebungen nicht im Original.

37 Margherita G. Sarfatti, Mussolini. Lebensgeschichte nach autobiographischen Unterlagen, Leipzig 1927, S. 73.

38 So hatte Mussolini auf einer Großkundgebung im Teatro Constanzi am 23. März 1924 Pareto in Rom als „uno dei miei maestri, il pi? illustre“ bezeichnet und sich im Herbst des gleichen Jahres auf einer Tagung der italienischen Volkswirtschaftslehrer noch einmal ausdrücklich auf ihn berufen. Vgl. Benito Mussolini, Opere omnia, Bd. 20, hrsg. von Edvardo und Duilio Susmel, Florenz 1956, S. 212.

39 Renzo de Felice, Mussolini il fascista, I. La conquista del potere: 1921-1925, Turin 1966, S. 306.

40 In Wirklichkeit handelte es sich beim „Marsch auf Rom“ um eine nachträgliche Inszenierung. Die Schwarzhemden rückten erst in Rom ein, nachdem Mussolini bereits ein Kabinett gebildet hatte und somit an die Spitze der Staatsmacht gelangt war. Vgl. Angelo Tasca, Glauben gehorchen kämpfen. Aufstieg des Faschismus, Wien / Frankfurt am Main / Zürich 1969, S. 355. 
Aus diesem offenkundigen Rezeptionszusammenhang ergeben sich folgende Schlüsse:

(1) Es kann kein Zweifel daran bestehen, dass das Parlamentarismusverständnis der APO von der präfaschistischen Liberalismuskritik Italiens beeinflusst wurde. Es weist zudem eine Reihe von Überschneidungen zu jener berühmt-berüchtigten von Carl Schmitt am Parlamentarismus der Weimarer Republik artikulierten Fundamentalkritik auf, die dieser ein Jahr später als Pareto artikulierte. ${ }^{41}$

(2) Die Form der von Pareto formulierten „Transformation der Demokratie“ war zwar weitgehend beibehalten worden, ihr Inhalt hatte politisch jedoch sozusagen die Seite gewechselt. Was zunächst für die extreme Rechte postuliert worden war, das sollte nun auf Seiten der extremen Linken Geltung haben.

(3) Agnoli greift Paretos Vorstellungen auf und überträgt sie auf die Bundesrepublik Deutschland zur Zeit der ersten Großen Koalition. Er übernimmt das Modell jedoch nicht einfach, sondern funktionalisiert es, indem er das Bild vom Parlament als einer massenwirksamen Fiktion benutzt, um das Repräsentationsorgan des bürgerlichen Staates grundlegend zu delegitimieren und damit Platz für eine nicht weiter konkretisierte Herrschaftsform als Alternative zu schaffen.

(4) In der Folge versucht er, seine Pareto-Adaption marxistisch im Sinne einer grundlegenden Kritik des Klassenstaates weiter auszuformulieren. ${ }^{42}$ Tatsächlich gelingt es ihm, einen zeitweilig in der Linken vakanten Platz zu besetzen - den einer als marxistisch geltenden Staatsanalyse als Teil einer gegenwartsbezogenen politischen Theorie. Diese im bundesdeutschen Neomarxismus vorhandene Lücke konnte schließlich weder von einem Vertreter der Frankfurter noch von einem der Marburger Schule ausgefüllt werden.

(5) Gleichwohl ist Agnolis Ansatz von einem grundlegenden Defizit gezeichnet: Seine Kritik bleibt in der bloßen Negation stecken. Er vermag keine handlungspolitische Option zu formulieren. Ebenso wenig wie er eine Vermittlung seiner Resultate in eine konstruktive Kritik der repräsentativen Demokratie erkennen lässt, findet sich bei ihm eine Übersetzung seiner verfassungsrechtlichen Analysen in praxisorientierte Alternativkonstruktionen. Übrig bleibt häufig nicht mehr als die anarchistische Attitüde eines emanzipatorisch kokettierenden, zuweilen selbstironischen, manchmal sogar clownesk auftretenden Professoren.

41 Carl Schmitt, Die geistesgeschichtliche Lage des heutigen Parlamentarismus, Berlin 1923. In einer der detailliertesten Untersuchungen über die ideengeschichtlichen Einflüsse des Staatstheoretikers auf die Bundesrepublik heißt es, dass „Die Transformation der Demokratie“ „einer der Schlüsseltexte für die ,linke' Carl-Schmitt-Rezeption“" gewesen sei. Dirk van Laak, Gespräche in der Sicherheit des Schweigens. Carl Schmitt in der politischen Geistesgeschichte der frühen Bundesrepublik, Berlin 1993, S. 290, Fn. 259, Hervorhebung nicht im Original.

42 Vgl. dazu insbesondere die Aufsatzsammlung: Johannes Agnoli, Überlegungen zum bürgerlichen Staat, West-Berlin 1975, mit den Beiträgen „Der Staat des Kapitals“ (S. 21 - 90), „Klasse und Staat in Deutschland“ (S. 90 - 111) sowie „Revolutionäre Strategie und Parlamentarismus" (S. $112-139)$. 


\section{Das Symposium über die SDS-Geschichte}

Im Juni 1985 veranstaltete das von Theo Pirker geleitete Zentralinstitut für sozialwissenschaftliche Forschung der Freien Universität ein zweitägiges Symposium über die Rolle des SDS in der Nachkriegszeit. ${ }^{43}$ Es erschienen nicht weniger als zwanzig Referenten und 200 weitere Teilnehmer, unter ihnen mit dem Stuttgarter Philosophen Günter Rohrmoser sowie dem Berliner Historiker Ernst Nolte auch zwei einflussreiche Konservative. ${ }^{44}$ Auf einem Panel zum Thema „Parlamentarismuskritik und die Konzeption der Basisdemokratie" entzündete sich ein Streit, in dessen Zentrum - kaum überraschend - die Rolle von Agnolis „Transformation der Demokratie“ geriet. Agnoli selbst war nicht zugegen.

Während der Rechtswissenschaftler Ulrich K. Preuß Agnoli vorhielt, er verkenne bei aller notwendigen Kritik die Möglichkeiten, die der Rechtsstaat biete, warf Werner Süß ihm Antipluralismus, einen homogenisierten Klassenbegriff und den Mangel einer Handlungsoption vor. Der Verfasser dieser Zeilen, der in seinem Vortrag das so genannte Organisationsreferat der beiden Wortführer des antiautoritären SDS-Flügels, Rudi Dutschke und Hans-Jürgen Krahl, problematisiert hatte ${ }^{45}$, schaltete sich in die Kontroverse mit der These ein, dass Agnoli seine Parlamentarismuskritik vor allem aus dem Denken präfaschistischer Theoretiker wie Vilfredo Pareto und Carl Schmitt bezogen habe. ${ }^{46}$ Darauf reagierte der Philosoph und Religionssoziologe Jacob Taubes, der sich selbst als „Links-Schmittianer“ zu erkennen gab, mit der Bemerkung, dass Schmitts Überlegungen ohne eine Verarbeitung des Leninismus nicht denkbar seien und es insofern durchaus legitim sei, die linke Parlamentarismuskritik aus dem rechten Entwurf zurückzuübersetzen. Da Preuß diesen Zusammenhang zurückzuweisen versuchte, ergriff Taubes erneut das Wort und behauptete, dass Agnoli Schmitts Parlamentarismuskritik „mit Löffeln gegessen“ habe. ${ }^{47}$ Agnolis Buch „Die Transformation der Demokratie“ sei 1968/69 nichts anderes als „die Schmittsche Variante der Relativisten“ gewesen. Während der Verfasser

43 Das Veranstaltungsprotokoll erschien erst mit einer Verzögerung von mehr als ein Dutzend Jahren: Siegward Lönnendonker (Hrsg.), Linksintellektueller Aufbruch zwischen „Kulturrevolution“ und „kultureller Zerstörung“. Der Sozialistische Deutsche Studentenbund in der Nachkriegsgeschichte 1946-1969. Dokumentation eines Symposiums, Opladen / Wiesbaden 1998.

$44 \mathrm{Vgl}$. das außerordentlich starke Presseecho an der Veranstaltung: Klaus Hartung, Die Rückkehr des SDS. Erstes SDS-Symposium an der Freien Universität Berlin. Zwischen Erinnerung und Selbstkritik, in: die tageszeitung vom 29. Juni 1985; Johannes Wendt, Zwischen Selbstprüfung und witzigen Anekdoten. Die SDS-Veteranen besinnen sich auf ihre Geschichte, in: Frankfurter Rundschau vom 16. Juli 1985; Jürgen Busche, Unsere Anführer haben uns nicht erklärt, warum wir diese Form der Bewegung wollten. Ehemalige SDS-Mitglieder diskutieren in Berlin über die APO von 1968, in: Frankfurter Allgemeine Zeitung vom 29. Juni 1985; Uwe Schlicht, Der Weg in die Gewalt. 17 Jahre danach: Das Jahr 1968 und die Außerparlamentarische Opposition. Treffen ehemaliger SDS-Mitglieder, in: Der Tagesspiegel vom 29. Juni 1985; Dieter Stäcker, Unter den Talaren Muff von 17 Jahren?, in: Deutsches Allgemeines Sonntagsblatt vom 7. Juli 1985.

45 Die erweiterte Fassung erschien später unter dem Titel: Autoritärer Staat und antiautoritäre Bewegung. Zum Organisationsreferat von Rudi Dutschke und Hans-Jürgen Krahl, in: 1999 Zeitschrift für Sozialgeschichte des 20. und 21. Jahrhunderts, 2. Jg. (1987), H. 3, S. $76-104$.

46 Siegward Lönnendonker (Hrsg.), Linksintellektueller Aufbruch, a.a.O., S. 295 f.

47 Ebenda, S. 292. Zu Parallelen und Differenzen zwischen der Parlamentarismuskritik Carl Schmitts und Johannes Agnolis vgl. Kurt Lenk, Wie demokratisch ist der Parlamentarismus, 2. verbesserte Auflage, Stuttgart / Berlin / Köln / Mainz 1974, S. 44 - 62. 
(W.K.) einen theoretischen Zusammenhang benannte, versuchte Taubes Agnoli in das Lager von Carl-Schmitt-Anhängern hinüberzuziehen. Der Journalist Johannes Wendt forderte Agnoli in einem Zeitungsbericht öffentlich zu einer Stellungnahme auf. ${ }^{48}$

Angesichts der um ihn entstandenen Dispute konnte es nur eine Frage der Zeit sein, bis Agnoli auf die in seiner Abwesenheit geführte Diskussion reagierte; und tatsächlich antwortete er - zum zwanzigsten Jahrestag seines Traktates in einer von ihm so genannten „Kommemorativabhandlung “49. Darin bezeichnete er das Berliner Symposium als „denkwürdige Veranstaltung“; den Verfasser versuchte er als Ignoranten abzukanzeln; von Taubes' Offerte zeigte er sich auch nicht geschmeichelt; auf Preuß und Süß, die sich in ihren Referaten ebenfalls kritisch mit der „Transformation der Demokratie“ auseinandergesetzt hatten, ging er hingegen mit keinem einzigen Wort ein.

Auffällig ist die Unverhältnismäßigkeit seiner schriftlichen Reaktion insgesamt. Weder der Verfasser noch Taubes hatten ausführlicher über Agnolis „Transformation der Demokratie" referiert; beide hatten, obgleich auf sehr unterschiedliche Weise, in der Diskussion mit nur wenigen Sätzen auf Rezeptionszusammenhänge hingewiesen, die ihnen evident zu sein schienen. Nun aber holte der auf diesem Symposium lediglich kurz Angesprochene zu einem schriftlichen Verteidigungsmarathon aus. Offensichtlich war bei ihm ein Nerv getroffen worden.

Zunächst aber versuchte Agnoli in seiner „Kommemorativabhandlung“ die Behauptung zu entkräften, dass Pareto ein Gegner des Verfassungsstaates gewesen sei. Der als „Marx der Bourgeoisie“ bezeichnete Soziologe sei für eine starke politische Klasse, die Herrschaft von Eliten, eine ungebremste kapitalistische Wirtschaft sowie die Beibehaltung des Parlaments eingetreten und in Wirklichkeit „ein rechtsgerichteter Altliberaler" gewesen. In seiner Schrift „Transformation der Demokratie“ ziehe er - als ginge ihm das gegen den Strich - Pareto „teilweise gewaltsam“ herbei, lediglich um aufzuzeigen, dass der Verfassungsstaat dessen Vorstellungen entspreche.

Die bereits seit langem gehegte Vermutung, dass es eine Berührung zwischen der rechts- und linksgerichteten Staatskritik im Allgemeinen und eine „Wahlverwandtschaft Schmitt-Agnol“ im Besonderen gebe, empfinde er schlicht als Zumutung, zu der er sich „nicht zu äußern" brauche; dennoch weist er dies, als wolle er auf Nummer sicher gehen, in dem einen Fall (Pareto) als eine angebliche Absurdität zurück und verweist sie in dem anderen (Schmitt) kurzerhand „ins Reich des ideologischen Trugs“.

Eines der von Agnoli bemühten Schlüsselworte stellte dabei der durch die Auseinandersetzung mit Jürgen Habermas in großen Teilen der Linken kontaminierte Begriff "Linksfaschismus" dar. Habermas hatte Dutschke bekanntlich auf dem nach den Trauerfeierlichkeiten für den von der Polizei am 2. Juni 1967 erschossenen Benno Ohnesorg vom Verband Deutscher Studentenschaften (VDS) organisierten Kongress „Bedingungen und Organisation des Widerstands“ mit den Worten attackiert: „Ich bin der Meinung, er hat

48 Johannes Wendt. „Agnoli wird sich noch äußern müssen.“ In: Frankfurter Rundschau vom 4. Juli 1985.

49 Bei einer Kommemoration kann es sich bekanntlich um eine Erinnerung, eine Gedächtnisfeier wie bei Allerseelen, aber auch um eine Fürbitte in einer Messe handeln. Vermutlich hatte der Katholik selbstironisch Letzteres im Sinn: Johannes Agnoli, Zwanzig Jahre danach, a.a.O. Das Periodikum "Prokla“ war aus einer Abspaltung von der Zeitschrift "Sozialistische Politik“ (SoPo) entstandenen, diese wiederum zuvor aus der „Berliner Zeitschrift für Politologie“, Nachfolgerin des Periodikums „Der Politologe“. 
eine voluntaristische Ideologie hier entwickelt, die man im Jahre 1848 utopischen Sozialismus genannt hat, und der unter heutigen Umständen, jedenfalls ich glaube, Gründe zu haben, diese Terminologie vorzuschlagen, linken Faschismus nennen muß. "50 Der hier erstmals an den charismatischen Wortführer des SDS adressierte Linksfaschismus-Vorwurf hinterließ tiefe Spuren. Er führte noch Wochen nach dem Kongress zu erhitzten Debatten und schuf eine nicht mehr zu überwindende Kluft zwischen dem SDS und seinem nunmehr ehemaligen Mentor Habermas. ${ }^{51}$

Agnoli griff diese Vokabel, die innerhalb der außerparlamentarischen Linken den Rang einer Verbalinjurie besaß, auf und bezichtigte nun den Verfasser gleich mehrfach, er habe ihn als Linksfaschisten und sein Werk als „linksfaschistische Parlamentarismuskritik" denunziert. ${ }^{2}$ Dies ist jedoch, wie der Blick ins Veranstaltungsprotokoll belegt, völlig unzutreffend. Darin heißt es im Gegenteil: „Ich glaube nicht, daß man daran vorbeikommt, daß der analytische Teil in Agnolis ,Transformation der Demokratie' im wesentlichen von Pareto vorgeprägt worden ist. Das heißt aber nicht, daß Agnoli ein präfaschistischer Theoretiker sei." ${ }^{33}$ Des Weiteren spekulierte Agnoli darüber, ob dem Verfasser vielleicht zu Ohren gekommen sein könne, dass er „im hohen Alter von 17 Jahren Linksfaschist gewesen" sei. ${ }^{54}$ Von biographischen Hintergründen war dem Verfasser zu dieser Zeit jedoch überhaupt nichts bekannt. Die auf der Konferenz geäußerte Kritik basierte allein auf einem textimmanenten Vergleich. ${ }^{55}$

Dann legte der wegen seines theoretischen Ansatzes in Zweifel Gezogene das überraschende Bekenntnis ab, er sei in der Tat - wie von seinem Kollegen Ekkehart Krippendorff behauptet - ein „revolutionärer Faschist“ und somit eigentlich ein "Linksfaschist" gewesen. Er wüsste im Übrigen nicht, fügte er selbstbewusst hinzu, warum er das leugnen solle. Es gehe dabei aber ausschließlich um eine „persönliche Kontinuität“, nicht um irgendeinen Zusammenhang mit seiner Schrift über „Die Transformation der Demokratie“. Dann lieferte er einige Episoden und Halbsätze, die nun belegen sollten, dass er im

50 Uwe Bergmann (Red.), Bedingungen und Organisation des Widerstandes. Der Kongreß in Hannover, West-Berlin 1967, S. 101

51 Vgl. dazu einen Sammelband, in dem neben den beiden Mentoren Wolfgang Abendroth und Peter Brückner die führenden Theoretiker des SDS ihre Gegenpositionen formulieren: Oskar Negt (Hrsg.), Die Linke antwortet Jürgen Habermas, Frankfurt am Main 1968.

52 Ebenda, S. 178.

53 Siegward Lönnendonker (Hrsg.), Linksintellektueller Aufbruch, a.a.O., S. 300.

54 „Irgendwann muß Kraushaar gehört oder gelesen haben, daß ich im hohen Alter von 17 Jahren Linksfaschist gewesen oder - wie Krippendorffreundlicherweise in der TAZ schrieb - ein ,revolutionärer Faschist'." Johannes Agnoli, Zwanzig Jahre, a.a.O., S. 15, Hervorhebungen nicht im Original.

55 Den Anstoß dazu hatte im Übrigen der Erziehungswissenschaftler und Publizist Micha Brumlik nach einer Diskussion über die Transformation von Protestbewegungen in Parteien gegeben. Brumlik, der 1969 Vorlesungen des britischen Politikwissenschaftlers Samuel Finer an der Hebräischen Universität in Jerusalem besuchte, hatte darin zum ersten Mal Näheres über Paretos Soziologie erfahren. Vgl. Micha Brumlik, Kein Weg als Deutscher und Jude. Eine bundesrepublikanische Erfahrung, München 1996, S. 88. Erst nach dem Berliner Symposium erhielt der Verfasser wiederum durch den Frankfurter Politikwissenschaftler Iring Fetscher, der an der Universität Tübingen Assistent von Agnolis späterem Doktorvater Eduard Spranger und knapp drei Jahrzehnte später an der Universität Frankfurt der Doktorvater des Verfassers war, einen Hinweis auf die frühen Jahre von Agnolis politischer Vergangenheit. 
Grunde bereits in den frühen 1940er Jahren Anleihen bei den Bolschewiki gemacht und, wie ihm amtlich bescheinigt worden sei, „außerhalb des Faschismus“ gestanden habe.

Wie ist Agnolis nachgeholte Entgegnung zu beurteilen? Die Behauptung, dass es sich bei der Einordnung Paretos in den politischen Zusammenhang vor der faschistischen Machteroberung, den italienischen Präfaschismus, um eine krasse Fehldeutung handle, ist unzutreffend. Schließlich hatte der als notorisch faschistenfreundlich geltende Soziologe im Herbst 1922 durch seine Empfehlungen nicht unerheblich dazu beigetragen, Mussolini davon abzuhalten, mit dem politischen System vollständig zu brechen und das Parlament gleich abzuschaffen. Ob Pareto damit, wie Giolitti etwa, den illusorischen Gedanken hegte, dass der Faschismus an der Macht eine Übergangserscheinung sei und bald wieder in den Verfassungsstaat integriert werden könne, ist nicht bekannt. Der bereits im Jahr darauf verstorbene Elitetheoretiker hat jedoch auf jeden Fall dem Mussolini-Faschismus in die Hände gearbeitet und als Ideologe eine aktive Rolle bei der Aushöhlung des Parlaments und dessen Umfunktionierung zu einem Illusionsraum für die Macht des Volkes gespielt.

Es ist unbestreitbar, dass es zwischen den Schmittschen und den Agnolischen Kategorien eine grundsätzliche Differenz gibt. Während es sich bei Schmitt - wie etwa im Falle seines Volksbegriffes - um naturalistische Termini handelt, so geht es bei Agnoli um gesellschaftspolitische und damit historische Begrifflichkeiten. Jedoch ist in einer Hinsicht eine aufschlussreiche Konvergenz zwischen beiden staats- und verfassungsrechtlichen Ansätzen zu diagnostizieren: Sie sind auf verschiedenartige Weise an Homogenitätsvorstellungen orientiert - Schmitt an solchen des Volkes und Agnoli an solchen der Klasse. Daraus resultiert eine zum Teil überraschend anmutende Nähe ihrer Kritikmuster - in dem einen Fall an der Weimarer, in dem anderen an der Bonner Demokratie. Beide sind erklärte Gegner des Liberalismus und einer pluralistischen Demokratievorstellung. Beide verurteilen aus prinzipiellen Erwägungen heraus die parlamentarische Demokratie und kritisieren ihre Einrichtungen in Grund und Boden. Während es dem einen auf eine regelrechte „Ausmerzung des Inhomogenen“ ankommt, all dessen, was als „volksfeindlich“ betrachtet wird, geht es dem anderen darum, den Klassenantagonismus zu schüren und die proletarische Klasse als eine unverbrüchliche Einheit zusammenzuschweißen.

Agnolis Eingeständnis, er sei in seiner Jugendzeit „Linksfaschist“ gewesen, entbehrt allerdings nicht einer gewissen Komik. Um offenbar einer eindeutigeren Zuordnung (und möglichen Verdammung) aus dem Weg zu gehen, stellte er sich plötzlich als einen frühen Anhänger der Oktoberrevolution, als Kapitalismuskritiker und Anhänger des Marxismus dar, der aus diesen Gründen damals bereits als „außerhalb des Faschismus“ stehend gemaßregelt worden sei. Im Grunde wollte er damit einem Selbstbild Nahrung geben, wonach er schon immer ein potentieller Antifaschist und Linker gewesen sei. Was aus seiner Sicht eine biographische „Schönung" war, wie noch zu konkretisieren sein wird, ist aus einer anderen Perspektive jedoch nichts anderes als eine unfreiwillige Bestätigung der von ihm so vehement in Abrede gestellten Hypothese, dass sich die Extreme von links und rechts zumindest berühren, wenn nicht gar in mancher Hinsicht überschneiden.

Letztlich war Agnoli in seiner Erwiderung beinahe allen Sachverhalten, die ihm nicht gerade in einer ad personam formulierten Kritik entgegengehalten worden waren, aus dem Weg gegangen. Weder war er auf die Herkunft der Formel von der „trasformazione della democrazia" in irgendeiner Weise eingegangen, noch hatte er sich auf die zentralen, 
auf dem Symposium in den Raum gestellten Kritikpunkte eingelassen, in welcher Weise er einem notorischen Antiparlamentarismus das Wort geredet hatte, geschweige denn, dass er die Hintergründe seiner frühen politischen und geistesgeschichtlichen Sozialisation in Italien unter der Herrschaft Mussolinis glaubhaft dargestellt hätte. Noch immer durfte er darauf vertrauen, dass er in der Öffentlichkeit von einer verbreiteten Unkenntnis der theoretischen wie biographischen Zusammenhänge profitieren konnte.

\section{Agnolis Biographie}

Was lange Zeit nur Eingeweihten bekannt war ${ }^{56}$, dann in den 1980 er Jahren immer mehr durchzusickern begann, wurde 2004 durch die von Barbara Görres Agnoli nach dem Tod ihres Mannes vorgelegte Biographie zur Gewissheit. ${ }^{57}$ Darin wird erstmals zusammenhängend aufgedeckt, was es mit Agnolis faschistischer - in seiner eigenen Terminologie „linksfaschistischer" - Vergangenheit auf sich hatte. Dem Band, der im Untertitel einschränkend als „biographische Skizze“ bezeichnet wird, lassen sich jedenfalls die wichtigsten Stationen aus Agnolis Lebenslauf entnehmen.

Geboren wurde er 1925 als Giovanni Agnoli in Valle di Cadore, einem kleinen in der Nähe von Cortina d'Ampezzo gelegenen Ort in den östlichen Dolomiten. Da er als Redakteur einer Schulzeitung frühzeitig Hymnen auf den Faschismus verfasst hatte, war es nicht weiter verwunderlich, dass er in seiner Provinz Anführer des faschistischen Jugendverbandes wurde. Agnoli war zudem ein glühender Bewunderer der deutschen Philosophie und verstand sich in dieser Zeit vor allem als Anhänger des Rechtshegelianers Ugo Spirito. ${ }^{58}$ Wie wichtig Agnoli in jenen Tagen gewesen sein muss, lässt sich daran erkennen, dass sein Name auf einer Hinrichtungsliste der Partisanen stand; erst in den 1960er Jahren erfuhr er, dass er wochenlang beschattet worden war, der Attentäter es jedoch nicht fertiggebracht hatte, seinen Auftrag auszuführen. Wegen seiner Bewunderung für das nationalsozialistische Deutschland meldete sich Agnoli - dessen Name in Johannes Aknoli „germanisiert" wurde - 1943 unmittelbar nach dem Abitur bei der Waffen-SS und wurde bald darauf Soldat der Deutschen Wehrmacht. ${ }^{59}$ Bis zum Kriegsende war er

56 So hieß es über seinen politischen Werdegang noch in der 1985 verbreiteten Ausgabe des Munzinger-Archivs fälschlicherweise, dass Agnoli „aus dem italienischen Linkssozialismus hervorgegangen" sei. Da die dort gemachten Angaben - bis zur Möglichkeit, auf diesem Weg auch die Privatadresse bekannt geben zu können - in der Regel von dem jeweils Porträtierten überprüft werden, darf die Vermutung gehegt werden, dass Agnoli an einer Aufdeckung seiner faschistischen Vergangenheit zumindest nicht gelegen war.

57 Barbara Görres Agnoli, Johannes Agnoli. Eine biographische Skizze, Hamburg 2004.

58 Vgl. Karin Priester, Der italienische Faschismus. Ökonomische und ideologische Grundlagen, Köln 1972, S. $308-316$.

59 In der Biographie seiner Witwe heißt es dazu: „Nach bestandener Abiturprüfung meldete Agnoli sich bei der Waffen-SS, die für ausländische Kriegsfreiwillige zuständig war. Aufgrund eines Abkommens zwischen der SS und der Wehrmacht, Freiwillige, die für das GebirgsjägerRegiment geeignet waren, diesem zuzuteilen, kam er zu den Gebirgsjägern." Barbara Görres Agnoli, Agnoli, a.a.O., S. 30. Inzwischen ist die Verfasserin dem Eindruck entgegengetreten, dass ihr späterer Mann mit diesem Schritt auch vorübergehend Mitglied der Waffen-SS gewesen sei. In einem von ihr verfassten Leserbrief heißt es dazu: „Die Behauptung, Agnoli habe sich freiwillig zur Waffen-SS gemeldet, ist falsch. Agnoli hat sich 1943 bei der Waffen-SS zur 
bei den Gebirgsjägern im Einsatz, vor allem zur Partisanenbekämpfung in Jugoslawien. ${ }^{60}$ Am 2. Mai 1945 nahmen ihn schließlich die Briten gefangen. Danach verbrachte er zwei Jahre als Kriegsgefangener in einem ägyptischen Lager.

Nach seiner Entlassung ging Aknoli 1948 nicht zurück in die Dolomiten, sondern durch Vermittlung eines deutschen Mitgefangenen nach Baden-Württemberg. Ein Jahr darauf begann er mit dem Studium der Philosophie an der Universität Tübingen. Sein wichtigster akademischer Lehrer wurde der Wilhelm Dilthey-Schüler Eduard Spranger, der ihn 1957 mit einer Dissertation über Giambattista Vicos Philosophie des Rechts promovierte. Im Nebenfach hatte Aknoli Politikwissenschaft bei Theodor Eschenburg belegt. Bereits zwei Jahre zuvor war er eingebürgert worden. Sein Nachname wurde wieder „re-italianisiert". Von nun an hieß er wieder Johannes Agnoli.

Nach dem dritten Wahlsieg der CDU im Jahre 1957 wurde der Politikwissenschaftler Mitglied der SPD, jedoch vier Jahre später zusammen mit anderen wegen seiner Unterstützung des SDS aus der Partei ausgeschlossen. Nach einer Assistenzzeit an der Universität Köln kam er 1962 an die Freie Universität Berlin. Durch maßgebliche Unterstützung des Politikwissenschaftlers Ernst Fraenkel erhielt er eine Lehrbefugnis. ${ }^{61}$ Die Hauptthemen seiner Vorlesungen waren der italienische Faschismus und der bürgerliche Staat. 1970 wurde Agnoli zum Assistenzprofessor ernannt, seine Habilitation erfolgte 1972. Das Thema seines Habilitationsvortrags, dessen Titel „Der technische Staat in der Auffassung von Ugo Spirito und Luigi Fontanelli" lautete, verriet, dass der ehemalige Mussolini-Anhänger offenbar immer noch nicht von den Ursprüngen seiner geistigen Biographie losgekommen war.

Viele seiner politischen Mitstreiter ließ Agnoli über seine faschistische Vergangenheit und seine Zeit als Soldat der Wehrmacht lange Zeit in Unkenntnis. ${ }^{62}$ Auch sind seinem Werk keine Hinweise darüber zu entnehmen, wie er sich vom Faschisten zum Sozialdemokraten und später zum Marxisten und radikalen Sozialisten gewandelt hat. Bis zu seinem Tod blieb er jedenfalls ein dezidierter Gegner des Staates. Auf die Frage nach dessen Gewaltmonopol, so wird berichtet, habe er immer nur mit der Bemerkung reagiert, dass Gewalt auf beiden Seiten gerechtfertigt sei. ${ }^{63}$ Eine mehr als nur taktische Befürwortung

deutschen Wehrmacht gemeldet. Der ,Umweg' war vorgeschrieben." Barbara Görres Agnoli, Bei der SS zur Wehrmacht gemeldet, in: Frankfurter Allgemeine Zeitung vom 17. Januar 2007, Hervorhebungen nicht im Original.

60 Dazu heißt es in offensichtlich entlastender Absicht, er sei lediglich Kompaniemelder gewesen und habe „auf den Feind nicht schießen dürfen“. Vgl. Barbara Görres Agnoli, Agnoli, a.a.O., S. 32.

61 Die Tatsache, dass der konstitutive Anti-Pluralist Agnoli durch den wichtigsten Theoretiker des Pluralismus in der bundesdeutschen Politikwissenschaft gefördert wurde, ist ein offenkundiges Paradox und erscheint immer noch erklärungsbedürftig zu sein.

62 Ein Bielefelder Soziologe berichtet inzwischen, was er 1958 auf einer Tagung in Vlotho mit dem dort als Referenten auftretenden Agnoli erlebt hat: „Beim abendlichen Rotwein hat er mit uns Achtzehnjährigen nicht nur Kampflieder der Roten im Spanischen Bürgerkrieg eingeübt, sondern auch sehr freimütig über die Ambivalenzen seiner Südtiroler Herkunft, seine Aktivitäten in faschistischen Organisationen und seine immer noch nicht ganz erloschenen Sympathien für Mussolinis radikalfaschistische Repubblica Sociale Italiana erzählt." Jürgen Frese, Agnolis Botschaft, in: Frankfurter Allgemeine Zeitung vom 21. Dezember 2006, Hervorhebung nicht im Original.

63 „Agnoli war gegen das Gewaltmonopol des Staats. Gewalt sei, wenn überhaupt, dann auf bei- 
von Wahlen kam für ihn nicht in Frage. Als mit den Grünen ein Spätprodukt der 68er-Bewegung in den Bundestag kam, lehnte er eine Unterstützung ihrer Politik strikt ab. ${ }^{64}$ Zum Schluss spielte er weder im akademischen Milieu noch in einer politischen Strömung eine maßgebliche Rolle. Eine Rezeption seiner Antiparlamentarismus-Doktrin findet heute fast nur noch in Randbereichen der Politikwissenschaft oder in Teilen der autonomen Bewegung statt, die ihn nicht zuletzt wegen seiner ostentativen Verachtung der parlamentarischen Demokratie und des Rechtsstaates wie eine Ikone verehren.

Die politische Biographie eines Theoretikers - so lässt sich einwenden - ist eine Seite, die Konsistenz seines Werkes und die Stichhaltigkeit seiner Argumente eine ganz andere. ${ }^{65}$ Warum sollte also - ist dann zu fragen - ein solcher Mann nach Kriegsende seine totalitäre Herkunft aus dem italienischen Faschismus nicht überwunden haben? So möglich dies ist, so wenig ist zu bestreiten, dass seiner Parlamentarismuskritik eine Illiberalität und ein Anti-Pluralismus inhärent sind, die mit dazu beigetragen haben, eine außerparlamentarische Bewegung und viele der aus ihr hervorgegangenen Gruppen und Organisationen in die Irre zu führen. Das, was zu Beginn der 1920er Jahre in Italien unter Vorzeichen der extremen Rechten postuliert worden war, wurde nun am Ende der 1960er Jahre in der Bundesrepublik Deutschland nur unwesentlich modifiziert unter Vorzeichen der extremen Linken argumentativ in Stellung gebracht.

\section{Die negative "Vollendung" der "Transformation der Demokratie“}

Agnoli hat seinen Ansatz bei wechselnden Anlässen und Gelegenheiten mit einem unverkennbaren Stoizismus verteidigt. Von politischen Veränderungen im Großen wie im Kleinen zeigte er sich im Hinblick auf die vermeintliche Gültigkeit seines Involutionstheorems unbeeindruckt. Je mehr die einstigen Akteure der APO und der aus ihrer Auflösung hervorgegangenen Nachfolgeorganisationen erkannten, dass sie mit ihrem AntiParlamentarismus in einer politischen Sackgasse gelandet waren, umso stärker insistierte Agnoli auf seinen einmal eingenommenen theoretischen Positionen. Trotz seiner gewachsenen akademischen und politischen Isolation hielt er daran nicht nur bis an sein Lebensende fest, sondern verstärkte sie bis zu einem imaginären Fluchtpunkt weiter. So erklärte er 1999 in einem Interview kategorisch: „Die Europa-Wahlen sind Scheinwahlen. Weil Europa [...] ein Schein ist; in Strasbourg tagt ein Scheinparlament - also sind die Europa-Wahlen Scheinwahlen." ${ }^{66}$ Und im Rückblick über die „Transformation der Demokratie“ konstatierte er: „Die Involutionstheorie ist ad acta zu legen. Die Involution ist perfekt geworden. Es ist keine Involutionstendenz mehr, sondern sie ist zu Ende geführt

den Seiten gerechtfertigt." Barbara Görres Agnoli, Agnoli, a.a.O., S. 76, Hervorhebung nicht im Original.

64 Dies schloss jedoch nicht aus, dass er im Sinne einer „Ausweitung des Dissenses“ in West-Berlin die zu den Grünen zählende Alternative Liste wählte. Vgl. Zwischen Bewegung und Institution. Ein Gespräch mit Johannes Agnoli, in: Wolfgang Kraushaar (Hrsg.), Was sollen die Grünen im Parlament?, Frankfurt am Main 1983, S. 120 - 138, S. 138.

65 Agnoli selbst soll Autobiographien grundsätzlich verachtet und Fragen nach seinem eigenen Lebenslauf immer nur spöttisch mit der Bemerkung abgewehrt haben: „Meine Biographie beginnt mit meiner Geburt." Vgl. Barbara Görres Agnoli, Agnoli, a.a.O., S. 10.

66 Johannes Agnoli, „Die Europa-Wahlen sind Scheinwahlen“, in: Jungle World vom 9. Juni 1999. 
worden. Man kann sagen, daß die berühmt-berüchtigte Transformation der Demokratie realisiert worden ist, daß sie überflüssig geworden ist." ${ }^{~} 67 \mathrm{Zu}$ diesem Zeitpunkt war für ihn die selbst prognostizierte Tendenz zur Gewissheit geworden. Der Transformationsprozess hatte sich erledigt, seiner theoretischen Figur war die Geschäftsgrundlage und seinem Buch der Gegenstand entzogen worden.

Als er im Mai 2003 starb, wurden in Nachrufen noch einmal die alten Klischees aktiviert. So charakterisierte ihn etwa mit Wolf-Dieter Narr einer seiner ehemaligen Kollegen vom Otto-Suhr-Institut als „Marxist, Kommunist und Anarchist“, ohne seine Vergangenheit - ob im italienischen Faschismus oder bei der Wehrmacht - auch nur mit einem einzigen Wort zu erwähnen. ${ }^{68}$ Damit war eine weitere Chance vergeben, am Lebensende eines Mannes Schlussfolgerungen aus dessen Scheitern zu ziehen und damit zugleich auch etwas vom durchaus tragischen Niedergang einer radikalen Linken zu begreifen, die sich ursprünglich zwar die Durchsetzung universeller Werte auf ihre Fahnen geschrieben hatte, ihre zumindest in der Tendenz totalitären Implikationen jedoch nicht durchschaute und deshalb nicht zuletzt wegen der Legitimationsschwäche ihres Demokratiemodells zu Fall gekommen war.

67 Ebenda.

68 „Johannes Agnoli - ein besonderer Mensch, wenn es denn einen solchen gegeben hat und gibt. Gerade darum kann er geradezu allgemein als Vorbild des Abweichens um aller menschlichen Vernunft willen wach gehalten werden." Wolf-Dieter Narr, Nachruf auf Johannes Agnoli, in: Graswurzelrevolution, Nr. 281, Sommer 2003; hier zitiert nach: http://www.graswurzel.net/ 281/agnoli.shtml [27. Januar 2007], Hervorhebung nicht im Original. 